\title{
Evaluation of Combination Antiemetic Therapy on CINV in Patients With Gynecologic Cancer Receiving TC Chemotherapy
}

\author{
MOTOTSUGU SHIMOKAWA ${ }^{1}$, TOSHINOBU HAYASHI ${ }^{2}$, TAKAHIRO KOGAWA ${ }^{3}$, REIKO MATSUI ${ }^{4}$, \\ MIKA MIZUNO ${ }^{5}$, FUMITAKA KIKKAWA ${ }^{6}$, TOSHIAKI SAEKI ${ }^{7}$, KEISUKE AIBA ${ }^{8}$ and KAZUO TAMURA ${ }^{9}$ \\ ${ }^{1}$ Clinical Research Institute, National Kyushu Cancer Center, Fukuoka, Japan; \\ ${ }^{2}$ Department of Pharmaceutical and Health Care Management, \\ Faculty of Pharmaceutical Sciences, Fukuoka University, Fukuoka, Japan; \\ ${ }^{3}$ Department of Developmental Therapeutics, National Cancer Center Hospital East, Chiba, Japan; \\ ${ }^{4}$ Department of Pharmacy, National Cancer Center Hospital East, Chiba, Japan; \\ ${ }^{5}$ Gynecologic Oncology, Aichi Cancer Center Hospital, Nagoya, Japan; \\ ${ }^{6}$ Department of Obstetrics and Gynecology, Nagoya University Graduate School of Medicine, Nagoya, Japan; \\ ${ }^{7}$ Department of Breast Oncology, Saitama Medical University International Medical Center, Saitama, Japan; \\ ${ }^{8}$ Department of Medical Oncology, Toda Central General Hospital, Saitama, Japan; \\ ${ }^{9}$ General Medical Research Center, Fukuoka University, Fukuoka, Japan
}

\begin{abstract}
Background/Aim: The incidence of delayed chemotherapy-induced nausea and vomiting (CINV), especially nausea, in gynecologic cancer patients who receive paclitaxel and carboplatin (TC) chemotherapy is unclear. We assessed risk factors for delayed CINV in these patients, and examined whether it was controlled with combination antiemetic therapy. Materials and Methods: Data were pooled from two prospective studies, and compared between the two antiemetic prophylaxis groups using inverse probability of treatment weighted (IPTW) analysis. Results: Among the 182 evaluable patients (mean age: 56.2 years), three antiemetics gave better overall control than two for delayed nausea $(42.9 \%$ vs. $57.4 \%$,) and vomiting (13.8\% vs. $34.5 \%)$. Risk factor for delayed nausea was age [odds ratio $(O R)=0.953 ; p=0.0898$ [ and use of two antiemetics (vs. three antiemetics) for delayed vomiting $(O R=0.304 ; p=0.0732)$. Conclusion: A combination of three antiemetics controls delayed CINV among patients who undergo TC chemotherapy. Identification of risk factors can facilitate personalized treatments.
\end{abstract}

Correspondence to: Dr. Mototsugu Shimokawa, Cancer Biostatistics Laboratory, Clinical Research Institute, National Kyushu Cancer Center 3-1-1 Notame, Minami-ku, Fukuoka 8111395, Japan. Tel: +81 925413231, Fax: +81 925418534, e-mail: shimokawa.m@nk-cc.go.jp

Key Words: Chemotherapy, nausea, vomiting, antiemetics, gynecologic cancer.
Chemotherapy-induced nausea and vomiting (CINV) are major adverse effects of cancer chemotherapy (1). CINV often causes delay or cessation of curative chemotherapy among cancer patients $(2,3)$. Antiemetic treatment has been remarkably improved by the development of such antiemetic agents as steroids, 5-hydroxytryptamine-3 receptor antagonists (5HT3RAs), and neurokinin-1 receptor antagonists (NK1RAs). International guidelines for antiemetic therapy prepared by organizations such as the American Society of Clinical Oncology (ASCO) (4), the Multinational Association of Supportive Care in Cancer (MASCC)/European Society of Medical Oncology (ESMO) (5), and the National Comprehensive Cancer Network (6) have been used worldwide. The 2010 Japanese guidelines for CINV (7) recommend 5HT3RAs and/or dexamethasone for moderate emetic-risk chemotherapy (MEC), and/or NK1RAs (aprepitant or fosaprepitant) for MEC regimens that contain carboplatin and irinotecan. Using these guidelines, oncologists began administering antiemetic drugs prophylactically, rather than after their patients developed CINV.

Recent international guidelines recommend a three-drug combination of an NK1RA, a 5HT3RA, and dexamethasone for delayed CINV for patients receiving carboplatin (4-6).

Although CINV in patients with gynecologic cancer who receive carboplatin-based regimens has been studied $(8,9)$, primary objectives of these studies compared two groups for the numbers of patients with complete responses (no vomiting and no rescue therapy). However, data are lacking on the incidence of, and risk factors for, CINV, especially nausea, among ovarian cancer patients receiving paclitaxel and carboplatin (TC) chemotherapy, which is a MEC. Risk 
factors associated with CINV have been reported as younger age, female sex, a history of CINV, and low alcohol consumption (10-18) for several solid tumors. Identifying risk factors for developing CINV among patients with gynecologic cancers is critical to their optimal treatment. Many aspects of CINV in ovarian cancer patients are unclear.

We hypothesized that adding an NK1RA is beneficial for antiemetic prophylaxis in TC-treated patients. Therefore, we assessed the efficacy of combination antiemetic therapy for both delayed vomiting and delayed nausea, and investigated their respective risk factors, in patients with TC-treated gynecologic cancers, based on two prospective cohort studies in Japan.

\section{Materials and Methods}

Patients and methods. Pooled patient-level data from two multicenter, prospective observational studies were analyzed. Individual study results were previously published or presented at a conference [study A, UMIN000005971 (18); study B, no registry number available (19)]. The study designs are summarized in Figure 1. Both studies were conducted in patients who were scheduled to receive MEC in Japan and were approved by the institutional review board or independent ethics committee of both sites involved in the study. Written informed consent was obtained from all participating patients before any related study procedure was initiated.

Data collection. Patients enrolled in either of the two studies were required to be at least 20 years of age, have a solid tumor, and be chemotherapy-naïve; data collection included 7-day diaries starting on the day of anticancer agent administration. CINV data were based on patient self-reports by diary. Eligible patients received two antiemetics, including palonosetron and/or older 5HT3RAs (i.e. azasetron, ramosetron, and granisetron), and dexamethasone, all of which were given within 1 hour before their scheduled TC treatments. Aprepitant was also an option in the combinations of two antiemetics. Each patient provided a complete history, including information on age, motion sickness, drinking habits, morning sickness, and antiemetics.

Statistical analysis. Patient demographics and incidence of delayed CINV were summarized using descriptive statistics or contingency tables and compared using Student's $t$-test or a chi-square test. An inverse probability of treatment weighted (IPTW) adjustment was used to account for selection bias of observable characteristics between the two antiemetics. Specifically, propensity scores that were derived from a logistic regression model that predicted receipt of 2 antiemetics versus 3 antiemetics were used to weight each patient with the aim of balancing out observable characteristics. Independent risk factors for delayed CINV were also evaluated using logistic regression analysis with the backward elimination method. $p<0.05$ (two-sided) was considered significant, except for independent risk factors (significance level was $p<0.1$ ). All statistical analyses were performed using SAS 9.4 (SAS Institute, Cary, NC, USA).

\section{Results}

Unweighted and weighted patient characteristics. A total of 182 patients were included in the analysis: 153 received two
Table I. Baseline characteristics.

\begin{tabular}{lccc}
\hline Characteristics & $\begin{array}{c}\text { Study A } \\
(\mathrm{N}=137) \\
\mathrm{n}(\%)\end{array}$ & $\begin{array}{c}\text { Study B } \\
(\mathrm{N}=45) \\
\mathrm{n}(\%)\end{array}$ & $\begin{array}{c}\text { Overall } \\
(\mathrm{N}=182) \\
\mathrm{n}(\%)\end{array}$ \\
\hline Mean age, years $\left(\mathrm{SD}^{\dagger}\right)$ & $56.1(10.39)$ & $54.9(10.48)$ & $56.2(10.34)$ \\
Motion sickness & & & \\
No & $100(73.0)$ & $32(71.1)$ & $132(72.5)$ \\
Yes & $37(27.0)$ & $13(28.9)$ & $50(27.5)$ \\
Drinking habit & $122(89.1)$ & $22(48.9)$ & $144(79.1)$ \\
No & $15(10.9)$ & $23(51.1)$ & $38(20.9)$ \\
Yes & & & $106(58.2)$ \\
Morning sickness & $81(59.1)$ & $25(55.6)$ & $76(41.8)$ \\
No & $56(40.9)$ & $20(44.4)$ & \\
Yes & & & $153(84.1)$ \\
Antiemetics & $108(78.8)$ & $45(100.0)$ & $29(15.9)$ \\
2 & $29(21.2)$ & $0(0.0)$ & \\
3 & & & \\
\hline
\end{tabular}

$\dagger$ SD: Standard deviation.

antiemetics and 29 received three antiemetics. Their baseline characteristics, including age, motion sickness, drinking habits, morning sickness, and antiemetic use, are shown in Table I. There were $137(75.3 \%)$ and 45 (24.7\%) patients in studies $\mathrm{A}$ and $\mathrm{B}$, respectively; their respective mean ages were 56.1 and 54.9 years; and their respective antiemetic use was $108(78.8 \%)$ and $45(100.0 \%)$ patients for 2 antiemetics, and $29(21.2 \%)$ and $0(0.0 \%)$ patients for 3 antiemetics.

Unweighted and weighted patient characteristics, stratified according to receipt of two or three antiemetics, are listed in Table II. Before IPTW adjustment, drinking habits significantly differed between the antiemetic groups $(p<0.0232)$. The propensity score between the 2-and 3antiemetic groups achieved adequate balance after IPTW adjustment, and all patient characteristics of age $(p=0.9750)$, motion sickness $(p=1.0000)$, drinking habit $(p=1.0000)$, and morning sickness $(p=1.0000)$ were similar between the antiemetic groups.

Control of CINV. The IPTW-adjusted incidence pattern of CINV after chemotherapy is shown in Figure 2. Incidence of delayed nausea was high for the entire cohort (56.4\%), but significantly differed between the 3-antiemetic group $(42.9 \%)$ and the 2 -antiemetic group $(57.4 \%)$. Incidence of delayed vomiting in the entire cohort was $28.0 \% ; 34.5 \%$ in the 2 -antiemetic group, and $13.8 \%$ in the 3 -antiemetic group.

Risk factors for CINV. Univariate and multivariate logistic regression analyses of risk factors for delayed CINV are shown in Table III. Age, motion sickness, drinking habits, morning sickness, and antiemetic regimen were analyzed. Although histories of motion sickness and morning sickness were identified as risk factors for delayed CINV, patients 
A nationwide survey of CINV study (study A)

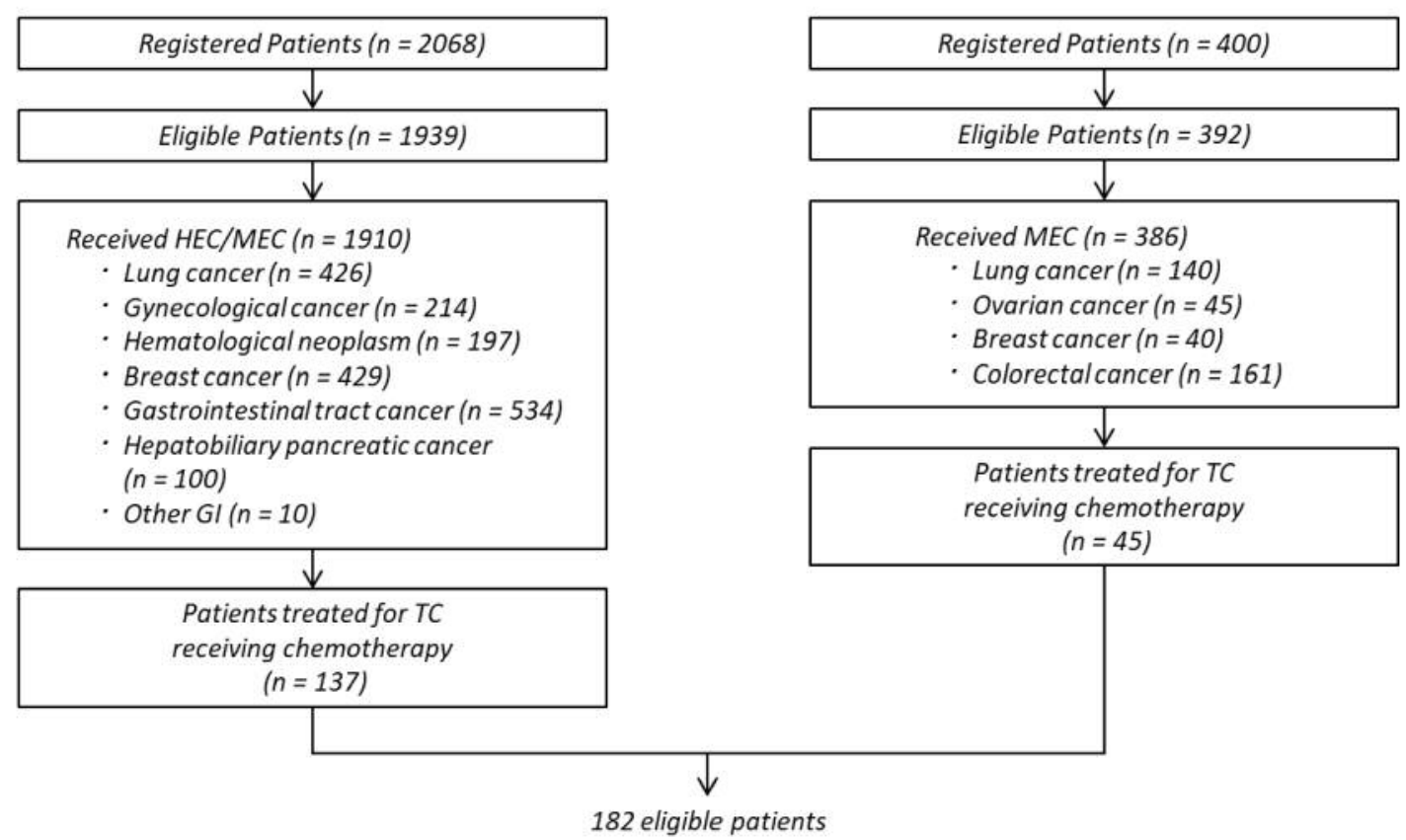

Prospective observational study of the 5 -HT3 receptor antagonist and dexamethasone as prophylaxis of CINV in MEC (study B)

Patients treated for TC

chemotherapy $n=45$

Figure 1. Patient selection diagram.

Table II. Baseline characteristics among unweighted and weighted study subjects between 2- and 3-antiemetic regimens.

\begin{tabular}{|c|c|c|c|c|c|c|}
\hline \multirow[t]{2}{*}{ Characteristics } & \multicolumn{3}{|c|}{ Unweighted } & \multicolumn{3}{|c|}{ Weighted, \% } \\
\hline & $\begin{array}{c}2 \text { antiemetics }(\mathrm{N}=153) \\
\mathrm{n}(\%)\end{array}$ & $\begin{array}{c}3 \text { antiemetics }(\mathrm{N}=29) \\
\mathrm{n}(\%)\end{array}$ & $p$-Value & 2 antiemetics & 3 antiemetics & $p$-Value \\
\hline Mean age, years $\left(\mathrm{SD}^{\dagger}\right)$ & $55.4(10.47)$ & $57.8(9.92)$ & 0.2540 & $57.84(10.33)$ & $57.79(9.92)$ & 0.9750 \\
\hline \multicolumn{7}{|l|}{ Motion sickness } \\
\hline No & $109(71.4)$ & $23(79.3)$ & 0.5057 & 79.11 & 79.32 & 1.0000 \\
\hline Yes & $44(28.8)$ & $6(20.7)$ & & 20.89 & 20.68 & \\
\hline \multicolumn{7}{|l|}{ Drinking habit } \\
\hline No & $116(75.8)$ & $28(96.6)$ & 0.0232 & 96.51 & 96.55 & 1.0000 \\
\hline Yes & $37(24.2)$ & $1(3.4)$ & & 3.49 & 3.45 & \\
\hline \multicolumn{7}{|l|}{ Morning sickness } \\
\hline No & $89(58.2)$ & 17 (58.6) & 1.0000 & 58.82 & 58.62 & 1.0000 \\
\hline Yes & $64(41.8)$ & $12(41.4)$ & & 41.18 & 41.38 & \\
\hline
\end{tabular}

$\dagger$ SD: Standard deviation.

who drank alcohol five times a week and who were older experienced CINV less frequently.

Older age was associated with less delayed nausea [OR=0.953; $90 \%$ Confidence Interval (90\% CI): 0.909$0.999 ; p=0.0898$ ], and use of 3-antiemetic regimens reduced delayed vomiting compared with 2 -antiemetic regimens $(\mathrm{OR}=0.304 ; 90 \% \mathrm{CI}=0.102-0.907 ; p=0.0732)$. 


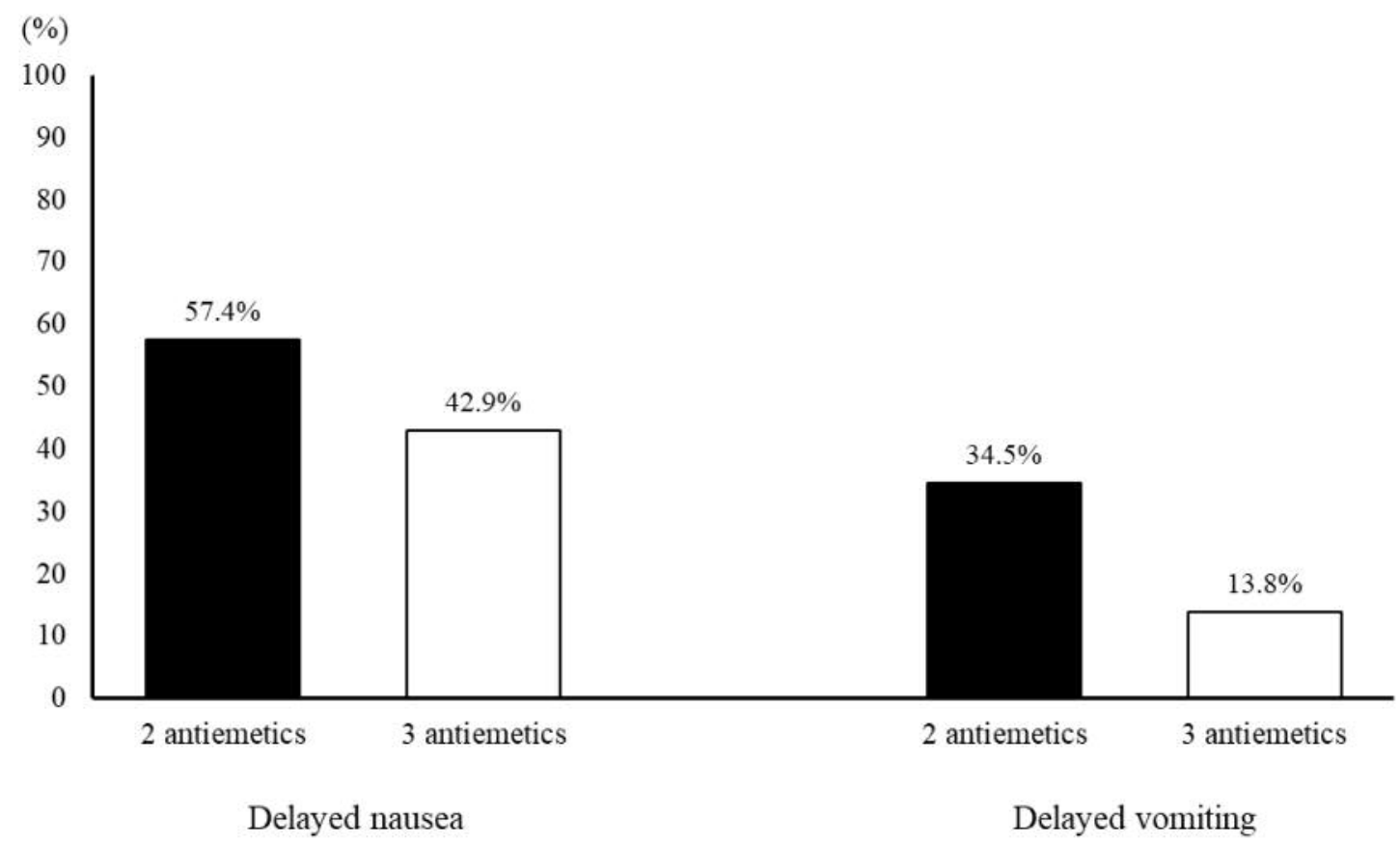

Figure 2. Incidence of delayed nausea and vomiting.

Table III. Risk factors for delayed nausea and delayed vomiting.

\begin{tabular}{|c|c|c|c|c|c|c|c|c|}
\hline & \multicolumn{4}{|c|}{ Delayed nausea } & \multicolumn{4}{|c|}{ Delayed vomiting } \\
\hline & \multicolumn{2}{|c|}{ Univariate } & \multicolumn{2}{|c|}{ Multivariate } & \multicolumn{2}{|c|}{ Univariate } & \multicolumn{2}{|c|}{ Multivariate } \\
\hline & $\mathrm{OR}^{\dagger}\left(90 \% \mathrm{CI}^{\ddagger}\right)$ & $p$-Value & OR $(90 \% \mathrm{CI})$ & $p$-Value & OR $(90 \% \mathrm{CI})$ & $p$-Value & OR $(90 \% \mathrm{CI})$ & $p$-Value \\
\hline Age & $\begin{array}{c}0.953 \\
(0.909-0.999)\end{array}$ & 0.0898 & $\begin{array}{c}0.953 \\
(0.909-0.999)\end{array}$ & 0.0898 & $\begin{array}{c}0.974 \\
(0.925-1.025)\end{array}$ & 0.3937 & & \\
\hline $\begin{array}{l}\text { Motion sickness: } \\
\text { Yes vs. no }\end{array}$ & $\begin{array}{c}1.244 \\
(0.426-3.629)\end{array}$ & 0.7375 & & & $\begin{array}{c}2.126 \\
(0.672-6.731)\end{array}$ & 0.2817 & & \\
\hline $\begin{array}{l}\text { Drinking habit: } \\
\text { Yes } v s . \text { no }\end{array}$ & $\begin{array}{c}0.374 \\
(0.027-5.137)\end{array}$ & 0.5369 & & & $\begin{array}{c}0.263 \\
(0.004-19.726)\end{array}$ & 0.6110 & & \\
\hline $\begin{array}{l}\text { Morning sickness: } \\
\text { Yes } v s \text {. no }\end{array}$ & $\begin{array}{c}1.469 \\
(0.601-3.590)\end{array}$ & 0.4791 & & & $\begin{array}{c}1.382 \\
(0.500-3.820)\end{array}$ & 0.6005 & & \\
\hline $\begin{array}{l}3 \text { antiemetics } v s \text {. } \\
2 \text { antiemetics }\end{array}$ & $\begin{array}{c}0.557 \\
(0.231-1.345)\end{array}$ & 0.2749 & & & $\begin{array}{c}0.304 \\
(0.102-0.907)\end{array}$ & 0.0732 & $\begin{array}{c}0.304 \\
(0.102-0.907)\end{array}$ & 0.0732 \\
\hline
\end{tabular}

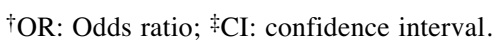

delayed nausea than did those who received two antiemetics. Incidence of delayed vomiting was relatively low, but was notably lower in patients who received a 3-antiemetic regimen. In patients undergoing TC chemotherapy, logistic regression analysis identified age as an independent risk factor for delayed nausea, and use of only two antiemetics for delayed vomiting.

Recent international guidelines on antiemetics (4-6) consistently recommend antiemetic prophylaxis regimens with three antiemetics (5HT3RAs, steroids and NK1RAs) for patients on carboplatin-based therapies or high emetic-risk chemotherapies (HEC). However, these recommendations are mostly based on trials that set complete responses as their primary endpoints, and evaluation for the prevention of nausea is not sufficient (4-6).

In gynecologic cancer patients who receive $\mathrm{TC}$ chemotherapy, some clinical trials $(20,21)$ have addressed 
3-antiemetic prophylaxis. However, Yahata et al. (21) reported, as a secondary endpoint, that aprepitant was effective in reducing nausea and vomiting in this setting.

Also, it is important to consider the risk/benefit profiles and drug costs when making treatment decisions, which also applies to antiemetics. Choosing Wisely, an initiative of the American Board of Internal Medicine (ABIM) Foundation that seeks to advance a national dialogue on avoiding unnecessary medical tests, treatments, and procedures, suggests that NK1RAs should not be used in patients who receive MEC, for tolerability and economic reasons (22).

Iihara et al. (23) reported that a 2-antiemetic regimen comprising a 5-HT3 receptor antagonist and dexamethasone was sufficiently effective to prevent CINV in most MEC regimens that included carboplatin. They saw no significant differences in the control of CINV among oxaliplatin, carboplatin, and irinotecan in that study.

Therefore, information that can guide healthcare professionals when designing antiemetic regimens for gynecologic cancer patients who undergo TC chemotherapy has not been lacking, especially in Japan.

A $10 \%$ difference in CINV rates seems to be clinically meaningful to the patient, as defined by MASCC/ESMO guidelines (24). This may be a useful threshold for changes in clinical practice. In the present study, 3-antiemetic regimens reduced incidences of delayed vomiting by $20.7 \%$ and delayed nausea by $14.5 \%$, compared with 2 -antiemetic regimens. Therefore, for patients who undergo TC chemotherapy, the prevention of CINV by a 3-antiemetic regimen is considered to be useful.

As mentioned above some well-known risk factors (such as younger age, female sex, history of CINV, and low alcohol consumption) for delayed CINV have been reported mainly from studies involving breast cancer patients. Furukawa et al. (25) reported that morning sickness was a risk factor for delayed vomiting in patients receiving a TC regimen with dexamethasone and granisetron. However, Tanioka et al. (26) found that morning sickness was not a significant risk factor in a study that compared the efficacy of aprepitant with two antiemetics in nondrinking women aged $<70$ years who were receiving MEC. Roscoe et al. (27) reported that a chemotherapy history was a stronger predictor than other predictors, including morning sickness, age, and motion sickness. Mizuno et al. (28) reported that morning sickness, $\mathrm{HEC}$, and young age were independent risk factors for delayed nausea in gynecological cancer patients receiving HEC or MEC. Our multivariate analysis found young age to be an independent risk factor for delayed nausea and 2-antiemetic regimens were an independent risk factor for delayed vomiting.

The present study had certain limitations. First, its design was neither randomized nor blinded, so our findings should be interpreted within the limitations of an observational study design. Second, the two integrated studies had some selection bias in their numbers of participants, which we attempted to mitigate using the IPTW method to balance observable characteristics of the 2- and 3-antiemetic regimens. Despite these limitations, the findings describe the incidence of CINV and its associated risk factors in routine clinical practice, rather than in a controlled trial.

In conclusion, a 3-antiemetic prophylactic combination is more effective than two antiemetics in preventing delayed CINV among patients with TC-treated gynecologic cancers. Identification of individual risk factors can facilitate personalized antiemetic treatments.

\section{References}

1 Grunberg SM, Osoba D, Hesketh PJ, Gralla RJ, Borjeson S, Rapoport BL, du Bois A and Tonato M: Evaluation of new antiemetic agents and definition of antineoplastic agent emetogenicity-an update. Support Care Cancer 13(2): 80-84, 2005.

2 Herrstedt J: Nausea and emesis: Still an unsolved problem in cancer patients? Support Care Cancer 10(2): 85-87, 2002.

3 Bloechl-Daum B, Deuson RR, Mavros P, Hansen M and Herrstedt J: Delayed nausea and vomiting continue to reduce patients' quality of life after highly and moderately emetogenic chemotherapy despite antiemetic treatment. J Clin Oncol 24(27): 4472-4478, 2006.

4 Hesketh PJ, Kris MG, Basch E, Bohlke K, Barbour SY, ClarkSnow RA, Danso MA, Dennis K, Dupuis LL, Dusetzina SB, Eng C, Feyer PC, Jordan K, Noonan K, Sparacio D, Somerfield MR and Lyman GH: Antiemetics: American society of clinical oncology clinical practice guideline update. J Clin Oncol 35(28): 3240-3261, 2017.

5 Roila F, Warr D, Hesketh PJ, Gralla R, Herrstedt J, Jordan K, Aapro M, Ballatori E and Rapoport B: 2016 updated mascc/esmo consensus recommendations: Prevention of nausea and vomiting following moderately emetogenic chemotherapy. Support Care Cancer 25(1): 289-294, 2017.

6 Nccn clinical practice guidelines in oncology (2018) antiemetics. Version 3 (2018). Available at: https://www.nccn.org/ professionals/ physician_gls/pdf/antiemesis.pdf. Accessed 30 July, 2018.

7 Takeuchi H, Saeki T, Aiba K, Tamura K, Aogi K, Eguchi K, Okita K, Kagami Y, Tanaka R, Nakagawa K, Fujii H, Boku N, Wada M, Akechi T, Udagawa Y, Okawa Y, Onozawa Y, Sasaki H, Shima Y, Shimoyama N, Takeda M, Nishidate T, Yamamoto A, Ikeda T and Hirata K: Japanese society of clinical oncology clinical practice guidelines 2010 for antiemesis in oncology: Executive summary. Int J Clin Oncol 21(1): 1-12, 2016.

8 Weinstein C, Jordan K, Green SA, Camacho E, Khanani S, Beckford-Brathwaite E, Vallejos W, Liang LW, Noga SJ and Rapoport BL: Single-dose fosaprepitant for the prevention of chemotherapy-induced nausea and vomiting associated with moderately emetogenic chemotherapy: Results of a randomized, double-blind phase iii trial. Ann Oncol 27(1): 172-178, 2016.

9 Rapoport BL, Jordan K, Boice JA, Taylor A, Brown C, Hardwick JS, Carides A, Webb T and Schmoll HJ: Aprepitant for the prevention of chemotherapy-induced nausea and vomiting associated with a broad range of moderately emetogenic chemotherapies and tumor types: A randomized, double-blind study. Support Care Cancer 18(4): 423-431, 2010. 
10 du Bois A, Meerpohl HG, Vach W, Kommoss FG, Fenzl E and Pfleiderer A: Course, patterns, and risk-factors for chemotherapyinduced emesis in cisplatin-pretreated patients: A study with ondansetron. Eur J Cancer 28(2-3): 450-457, 1992.

11 Hesketh P, Navari R, Grote T, Gralla R, Hainsworth J, Kris M, Anthony L, Khojasteh A, Tapazoglou E, Benedict C and Hahne W: Double-blind, randomized comparison of the antiemetic efficacy of intravenous dolasetron mesylate and intravenous ondansetron in the prevention of acute cisplatin-induced emesis in patients with cancer. Dolasetron comparative chemotherapy-induced emesis prevention group. J Clin Oncol 14(8): 2242-2249, 1996.

12 Osoba D, Zee B, Pater J, Warr D, Latreille J and Kaizer L: Determinants of postchemotherapy nausea and vomiting in patients with cancer. Quality of life and symptom control committees of the national cancer institute of canada clinical trials group. J Clin Oncol 15(1): 116-123, 1997.

13 Pater J, Slamet L, Zee B, Osoba D, Warr D and Rusthoven J: Inconsistency of prognostic factors for post-chemotherapy nausea and vomiting. Support Care Cancer 2(3): 161-166, 1994.

14 Pollera CF and Giannarelli D: Prognostic factors influencing cisplatin-induced emesis. Definition and validation of a predictive logistic model. Cancer 64(5): 1117-1122, 1989.

15 Research IGfA: Persistence of efficacy of three antiemetic regimens and prognostic factors in patients undergoing moderately emetogenic chemotherapy. Italian group for antiemetic research. J Clin Oncol 13(9): 2417-2426, 1995.

16 Roila F, Boschetti E, Tonato M, Basurto C, Bracarda S, Picciafuoco M, Patoia L, Santi E, Penza O, Ballatori E et al: Predictive factors of delayed emesis in cisplatin-treated patients and antiemetic activity and tolerability of metoclopramide or dexamethasone. A randomized single-blind study. Am J Clin Oncol 14(3): 238-242, 1991.

17 Roila F, Tonato M, Basurto C, Bella M, Passalacqua R, Morsia $\mathrm{D}$, DiCostanzo F, Donati D, Ballatori E, Tognoni G and et al:: Antiemetic activity of high doses of metoclopramide combined with methylprednisolone versus metoclopramide alone in cisplatin-treated cancer patients: A randomized double-blind trial of the italian oncology group for clinical research. J Clin Oncol 5(1): 141-149, 1987.

18 Tamura K, Aiba K, Saeki T, Nakanishi Y, Kamura T, Baba H, Yoshida K, Yamamoto N, Kitagawa Y, Maehara Y, Shimokawa M, Hirata K, Kitajima $M$ and Japan CSGo: Testing the effectiveness of antiemetic guidelines: Results of a prospective registry by the cinv study group of Japan. Int J Clin Oncol 20 : 855-865, 2015.

19 Sugita RM, Suzuki K, Takiguchi T, Nishio M, TKoike T, Hayashi T, Seto T, Kogure Y, Nogami N, K. Fujiwara K, Kaneda H, Harada T, Shimizu S, Kimura M, Kenmotsu $\mathrm{H}$,Shimokawa $\mathrm{M}$ and Goto $\mathrm{K}$ : The multicenter, prospective observational study of the 5-ht3 receptor antagonist and dexamethasone as prophylaxis of chemotherapy-induced nausea and vomiting (cinv) in moderately emetic chemotherapy (mec) for solid tumors. Eur J Cancer 51: S238, 2015.

20 Choi CH, Kim MK, Park JY, Yoon A, Kim HJ, Lee YY, Kim TJ, Lee JW, Kim BG and Bae DS: Safety and efficacy of aprepitant, ramosetron, and dexamethasone for chemotherapy-induced nausea and vomiting in patients with ovarian cancer treated with paclitaxel/carboplatin. Support Care Cancer 22(5): 1181-1187, 2014.
21 Yahata H, Kobayashi H, Sonoda K, Shimokawa M, Ohgami T, Saito T, Ogawa S, Sakai K, Ichinoe A, Ueoka Y, Hasuo Y, Nishida M, Masuda S and Kato K: Efficacy of aprepitant for the prevention of chemotherapy-induced nausea and vomiting with a moderately emetogenic chemotherapy regimen: A multicenter, placebo-controlled, double-blind, randomized study in patients with gynecologic cancer receiving paclitaxel and carboplatin. Int J Clin Oncol 21(3): 491-497, 2016.

22 ABIM: Choosing wisely: Ten things physicians and patients should question, 2013.

23 Iihara H, Ishihara M, Fujii H, Yoshimi C, Yamada M, Suzuki A, Yamaguchi K, Futamura M, Yoshida K and Itoh Y: Comparison of the control of nausea and vomiting among several moderately emetic-risk chemotherapy regimens. J Cancer 7(5): 569-575, 2016.

24 Roila F, Herrstedt J, Aapro M, Gralla RJ, Einhorn LH, Ballatori E, Bria E, Clark-Snow RA, Espersen BT, Feyer P, Grunberg SM, Hesketh PJ, Jordan K, Kris MG, Maranzano E, Molassiotis A, Morrow G, Olver I, Rapoport BL, Rittenberg C, Saito M, Tonato M, Warr D and Group EMGW: Guideline update for mascc and esmo in the prevention of chemotherapy- and radiotherapyinduced nausea and vomiting: Results of the perugia consensus conference. Ann Oncol 21: v232-243, 2010.

25 Furukawa N, Akasaka J, Shigemitsu A, Sasaki Y, Nagai A, Kawaguchi $\mathrm{R}$ and Kobayashi $\mathrm{H}$ : Evaluation of the relation between patient characteristics and the state of chemotherapyinduced nausea and vomiting in patients with gynecologic cancer receiving paclitaxel and carboplatin. Arch Gynecol Obstet 289(4): 859-864, 2014.

26 Tanioka M, Kitao A, Matsumoto K, Shibata N, Yamaguchi S, Fujiwara K, Minami H, Katakami N, Morita S and Negoro S: A randomised, placebo-controlled, double-blind study of aprepitant in nondrinking women younger than 70 years receiving moderately emetogenic chemotherapy. Br J Cancer 109(4): 859-865, 2013.

27 Roscoe JA, Bushunow P, Morrow GR, Hickok JT, Kuebler PJ, Jacobs A and Banerjee TK: Patient expectation is a strong predictor of severe nausea after chemotherapy: A university of rochester community clinical oncology program study of patients with breast carcinoma. Cancer 101(11): 2701-2708, 2004.

28 Mizuno M, Hiura M, Kikkawa F, Numa F, Yaegashi N, Narahara H, Aoki D, Kimura E, Kato H, Shimokawa M, Sugiyama T and Kamura T: A prospective observational study on chemotherapyinduced nausea and vomiting (cinv) in patients with gynecologic cancer by the cinv study group of japan. Gynecol Oncol 140(3): 559-564, 2016.
Received November 21, 2018

Revised November 29, 2018

Accepted November 30, 2018 